\title{
Skin Rash
}

National Cancer Institute

\section{Source}

National Cancer Institute. Skin Rash. NCI Thesaurus. Code C39594.

Any change in the skin which affects its appearance or texture. A rash may be localized to one part of the body, or affect all the skin. Rashes may cause the skin to change color, itch, become warm, bumpy, dry, cracked or blistered, swell and may be painful. 